\title{
Importance of complex diagnostic approach in differential diagnosis of alveolar echinococcosis
}

\author{
M. SZILÁGYIOVÁ1, L'. LACA², D. ANTOLOVÁ3 E. NOVÁKOVÁ4, R. ROSOLANKA' ${ }^{1}$, K. REITEROVÁ ${ }^{3}$ K. ŠIMEKOVÁ ${ }^{*}$
}

${ }^{1}$ Clinic of Infectology and Travel Medicine, Comenius University Bratislava, Jessenius Faculty of Medicine and University Hospital, Martin, *E-mail: simekova@jfmed.uniba.sk; ${ }^{2}$ Clinic of Surgery and Transplantation Centre, Jessenius Faculty of Medicine and University Hospital, Martin; ${ }^{3}$ nstitute of Parasitology of Slovak Academy of Sciences, Košice; ${ }^{4}$ Department of Microbiology and Immunology, Comenius University Bratislava, Jessenius Faculty of Medicine, Martin

Article info

Received June 2, 2015

Accepted June 23, 2015

\begin{abstract}
Summary
Alveolar and cystic echinococcosis, serious parasitic diseases caused by larval stages of Echinococcus multilocularis and E. granulosus has been diagnosed in Slovakia for a long time. Study presents case of 49-years old patient with accidentally diagnosed one big $(60 \mathrm{~mm})$ and multiple small (2- $24 \mathrm{~mm}$ ) hypoechogenic structures localised in right liver lobe. According to positive serology to $E$. granulosus antigen and results of imaging examinations the patient was classified as possible case of cystic echinococcosis and treated with mebendazole. Later, due to the worsening of clinical, laboratory and CT findings surgical biopsy was performed and surgical biopsy and subsequent PCR examination of liver tissue confirmed the diagnosis of alveolar echinococosis. Clinical picture of disease imitating cystic echinococcosis in presented case report, together with results of serological tests confirmed importance of accurate differential diagnosis of echinococcosis. Each aspect of clinical and laboratory results should be considered responsibly, however, sometimes only molecular techniques can solve the problem of differential diagnosis.
\end{abstract}

Keywords: alveolar echinococcosis; cystic echinococcosis; differential diagnosis; therapy

\section{Introduction}

Autochthonous alveolar echinococcosis (AE) has been diagnosed in Slovakia since 2000. This serious parasitic disease, caused by larval stages of Echinococcus multilocularis, can cause the death of untreated patient in ten to fifteen years after the diagnosis. The prevalence of the parasite in red foxes (Vulpes vulpes), definitive hosts of the parasite, is about $30 \%$, but regionally, mostly in the northern areas of the country, overreaches $60 \%$ (Miterpáková \& Dubinský, 2011). Between 2000 and 2014, 37 human cases of alveolar echinococcosis were confirmed in Slovakia and the majority of patients originated from northern, endemic areas of the country (Antolová et al., 2014). Of them, 26 cases were diagnosed at the Clinic of Infectology and Travel Medicine in Martin. While only four patients were confirmed between 2000 and 2005, in the period of 2006 and 2014 there was 22 new cases recorded. It confirms the continuing increase of human patient's number and the importance of proper diagnostic and therapeutic approaches in management of the disease. The description of selected case reports the litera- ture together with the presentation of the problems in diagnosis and therapy of some patients was published previously (Szilágyiová et al., 2001; 2005; 2011; 2014; Kinčeková et al., 2002). Cystic echinococcosis (CE) is also a matter of significant concern of public health (Manfredi et al., 2013) and E. granulosus, its etiological agent, has been known to occur in Slovakia for a long time (Turčeková et al., 2009) with human cases of the disease reported occasionally.

Usually, unspecific clinical symptoms, long incubation period and cross-reactivity between $E$. multilocularis and $E$. granulosus in serological examination complicate the diagnostics of alveolar and cystic echinococcosis in humans. Correct confirmation of diagnosis, together with the identification of etiological agent of disease is therefore essential not only for the prognosis estimation, but especially for the proper and correct treatment of the patient.

Study presents, on the basis of case report description, the input of serological and molecular methods in differential diagnosis of ethiological agens of echinococcosis (E. granulosus versus $E$. multilocularis) and their positive impact on further therapeutic approach. 


\section{Case report}

In 49 years old female patient living in the village, liver impairment was diagnosed during the preoperational examinations for hallux valgus surgery. Ultrasonography (USG) of the liver disclosed several hypoechogenic structures in the parenchyma. Following computer tomography (CT) and magnetic resonance imaging (MRI) showed the presence of partly homogenous formation with dimensions of $78 \times 80 \mathrm{~mm}$, with the presence of round focuses inside the structure. The formation was irregular in shape and bounded by lighter turned rim. Moreover, several round hypodense focuses, 2 $24 \mathrm{~mm}$ in diameter, were observed in the liver parenchyma (Fig. 1). The patient was referred to Clinic of Infectology and Travel Medicine for the consultation due to the suspicion of parasitic disease. During clinical examination the patient did not indicate any subjec- ment with mebendazole (1000 mg/day) was initiated. During the control examination 10 months later, the antibody titres to $E$. granulosus decreased to 1:100 and laboratory finding normalised in values of aminotransferases and eosinophils. Although GMT decreased significantly $(1.2 \mu \mathrm{kat} / \mathrm{l})$ it was still over the reference value (Table 1). A repeated CT examination showed that hypodense structure in $S 7 / 8$ increased in size and reached $80 \times 78 \times 85 \mathrm{~mm}$ with calcification in the centre. In other parts of the right and left liver lobe, there were almost 80 small cystic lesions detected, with diameter ranging from 3 to $10 \mathrm{~mm}$. Laterally, another cystic structure with the size of $26 \times 23 \times 28 \mathrm{~mm}$ was localised subcapsularly in $S 6 / 7$ segment, what definitely confirmed the progression of the process. Consultation with the surgeon did not bring the recommendation for radical operation because of the localisation and extensive spread of the liver process.

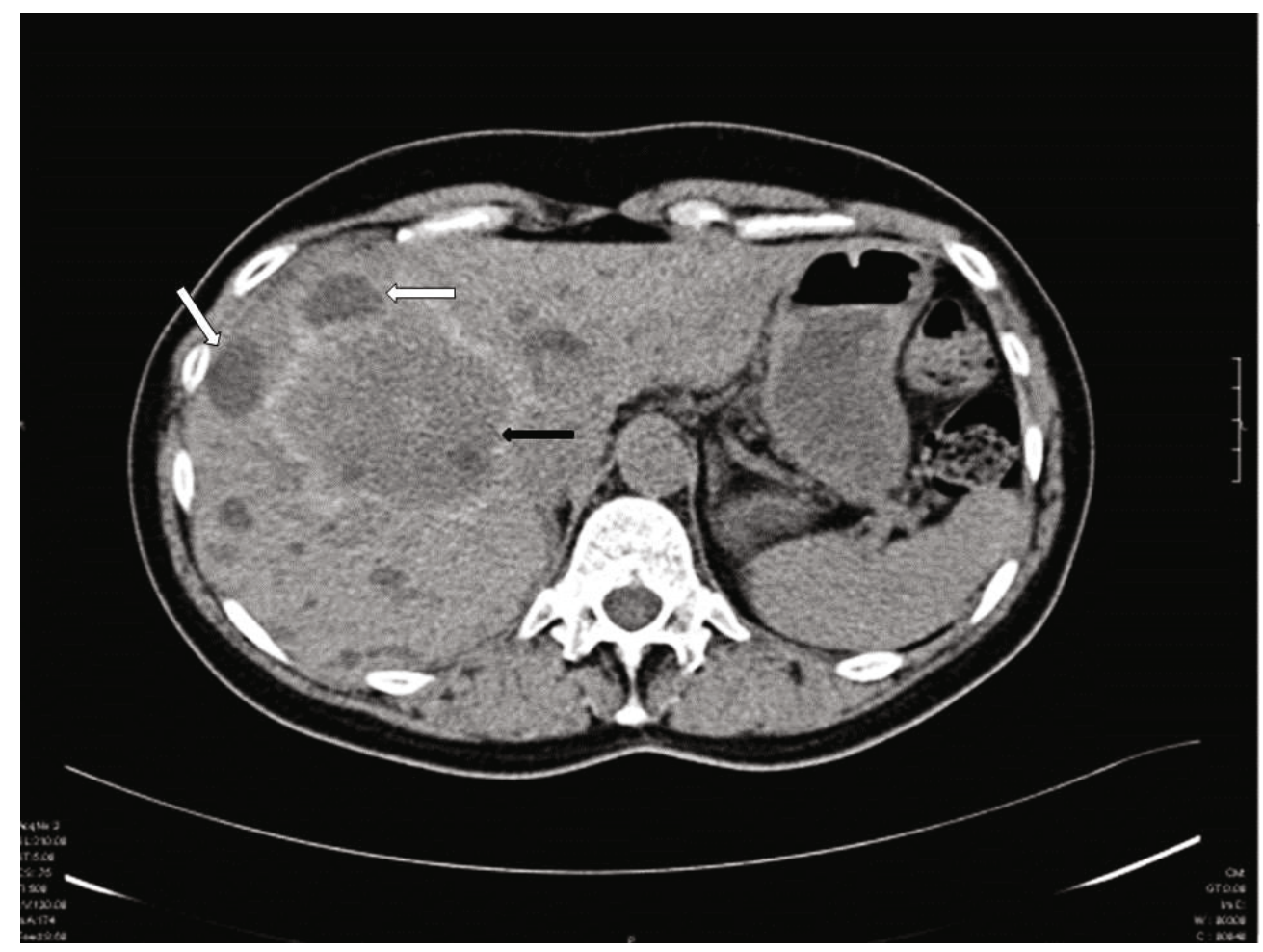

Fig. 1. Findings of computer tomography $(\mathrm{CT})$ with contrast substance after the first contact with the patient. Black arrow shows the main parasitic focus, white arrows show two smaller daughter cysts. In addition, there are number of smaller focuses affecting almost all areas of the liver

tive problems. In epidemiological history she gave the information about the keeping of the dog in the household and consummation of forest fruits. Besides the hepatomegaly $(+2 \mathrm{~cm})$, the objective findings were negative. Laboratory test findings are shown in the Table 1 and CT imaging did not confirm any metastatic focuses in other organs.

Serological ELISA examinations for the presence of antibodies to Echinococcus spp. using E. granulosus antigen B and E. multilocularis somatic antigen were performed according to Reiterová et al. (2014). The result showed the presence of medium titres (1:400-800) of antibodies to E. granulosus and no antibodies titres to $E$. multilocularis.

With regard to results of serological and imaging examinations the diagnosis of cystic echinococcosis was suspected and the treat-
During the next control examination 6 months later, the patient complained for intermittent pressure pain in the right hypochondriac area depending on the position of the body. Laboratory findings discovered the elevation of GMT to $11.04 \mu \mathrm{kat} / \mathrm{l}$ (Table 1) and CT findings did not show any improvement. Therefore, 2.5 years after the beginning of the therapy, the surgery revision and liver biopsy were performed. After the opening of abdominal cavity, the oedematous liver could be seen with multiple small tumours in the left and right lobes, ranging between 2 and $5 \mathrm{~mm}$ in diameter. Some of them were black; others were whitish and tough in consistency. In the right lobe, there was the tumour with nonhomogeneous structure, approximately $10 \mathrm{~cm}$ in diameter. Nor right hepatic vein, nor retroperitoneal part of vena cava inferior was detectable. Gallbladder was involved in adhesions, without infiltra- 
Table 1. Results of laboratory examinations

\begin{tabular}{|c|c|c|c|c|}
\hline \multirow{2}{*}{ PARAMETER } & \multicolumn{3}{|c|}{ VALLUE } & \multirow{2}{*}{ REF. VALUES* } \\
\hline & First contact & After 10 months & After 6 months & \\
\hline $\begin{array}{l}\text { ALT ( } \mu \text { kat/l) } \\
\text { (Alanin Aminotransferase ) }\end{array}$ & 1.11 & $\mathrm{~N}$ & $\mathrm{~N}$ & $<0.70$ \\
\hline $\begin{array}{l}\text { AST ( } \mu \text { kat } / l) \\
\text { (Aspartat Aminotranferase) }\end{array}$ & 1.07 & $\mathrm{~N}$ & $\mathrm{~N}$ & $<0.60$ \\
\hline $\begin{array}{l}\text { GMT ( } \mu \text { kat/l) } \\
\text { (Gama-glutamyl Transferase) }\end{array}$ & 7.35 & 1.2 & 11.04 & $<0.86$ \\
\hline Eosinophils (x 109/I) & 0.6 & $\mathrm{~N}$ & $\mathrm{~N}$ & $<0.3$ \\
\hline
\end{tabular}

*Reference values; $\mathrm{N}$ - results were within reference values

tions (Fig. 2). Lymphadenectomy performed from hepatoduodenal ligament revealed the presence of several venous convolutions inside. The part of left liver lobe was resected, as well as the material from the border part of the tumour in the right lobe.

Histological evaluation of lymphatic node confirmed the signs of chronic antigenic stimulation without signs of malignancy. In the subcapsular sample of the liver tissue, original parenchyma was completely replaced by necrotic material, with the rests of homogenous eosinophilic $\mathrm{PAS}^{+}$segments (lamellas). The histiocytic resorption rime with formation of nonspecific granular tissue and chronic inflammation were detected in the surroundings of the necrosis. In the conclusion, histologist suggested suspicious echinococcosis of the liver.

Molecular examination of liver tissue sample was realised on the
Institute of Parasitology SAS. PCR amplification of mitochondrial NAD1 and NAD2 gene performed with specific E. multilocularis primer pairs according to Schneider et al. (2008) and Nakao et al. (2009) confirmed the presence of $E$. multilocularis DNA in the sample. Subsequent sequencing of NAD2 gene amplification product confirmed the diagnosis of alveolar echinococcosis.

The surgeon had considered the possibility of the liver transplantation but the patient disagreed. Therefore, therapeutic doses of mebendazole were increased to $50 \mathrm{mg} / \mathrm{kg}$ and regular control settings in out-patient department were realised. Fourteen months after the surgery and the change of the therapy, the aminotransferases values corrected to normal range, the GMT value decreased to $3.2 \mu \mathrm{kat} / \mathrm{l}$ and MRI confirmed mild tendency of improvement of the local findings.

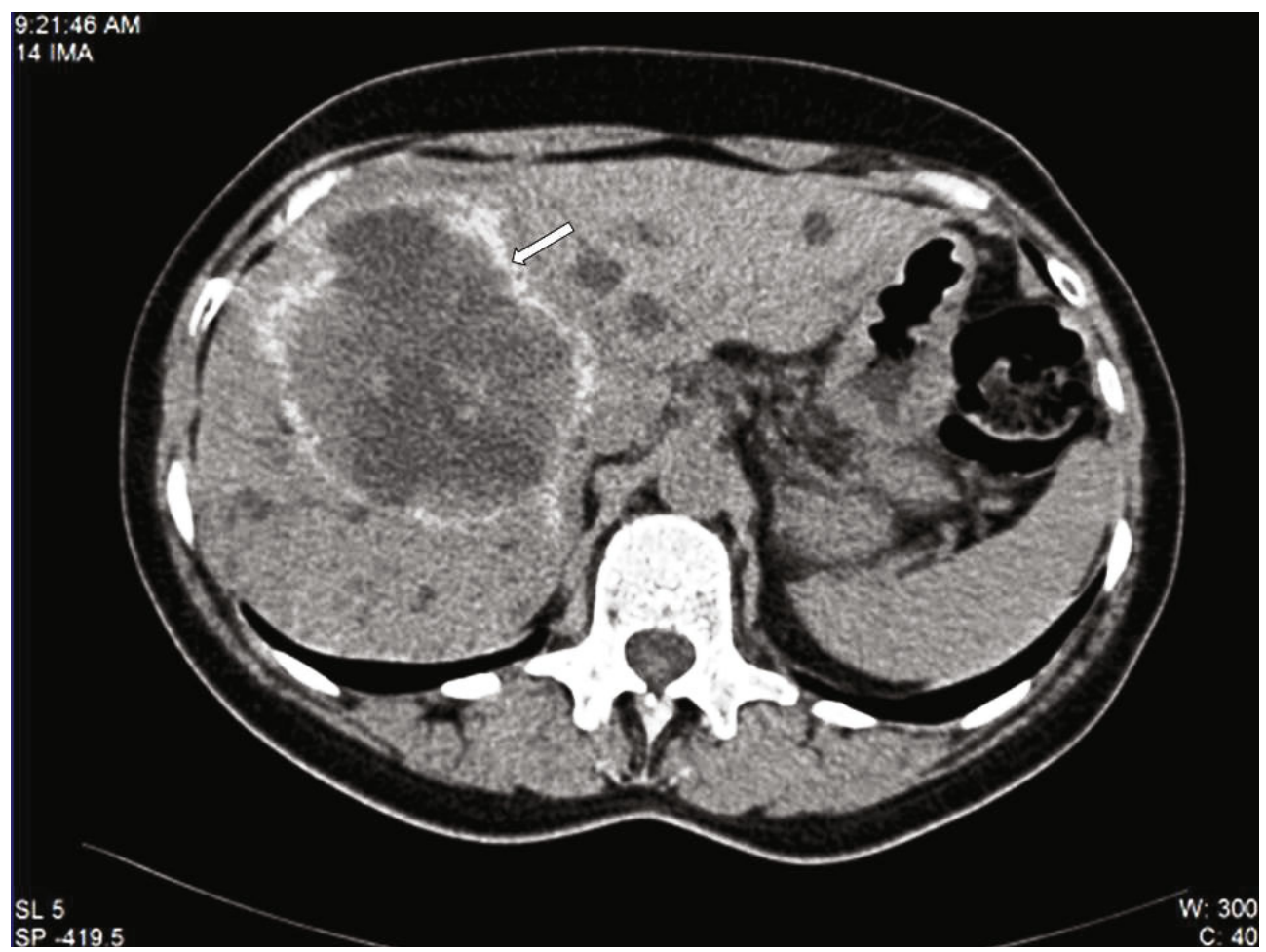

Fig. 2. Result of CT examination performed before surgery. Control CT finding shows considerably enlarged parasitic focus (white arrow) when comparison to the first $\mathrm{CT}$ image 
MRI examination from March 2015 showed the presence of multiple, cystoid shape tumours $2-24 \mathrm{~mm}$ in diameter in the liver. They were hypodense in the T1 and hyperdense in T2 area. There were also few isolated focuses with the signs of partial regression of its size. In S 5/6 segment, relatively homogenous expansion (90 $x 77 \mathrm{~mm}$ ), with the liquid in the centre was observed. Peripheral rime, almost $2.5 \mathrm{~cm}$ thick, was less intensive when compared to the normal liver parenchyma. The structure was without growth progression when compared with the previous MRI examination. According to MRI result performed one year before, it could be concluded that the biggest liver focus is stable and smaller structures are sporadically in mild regression.

\section{Discussion}

Both, E. multilocularis and E. granulosus occur in Slovakia, therefore alveolar as well as cystic echinococcosis should be considered within the differential diagnosis of liver cystic and vesicular structures. Larval stage of $E$. multilocularis usually proliferates in affected organ as a multivesicular structure and may involve several liver segments, expand along liver vessels and biliary tract, and finally infiltrates neighbouring organs (Kern et al., 2006). It is characterised by the parasitic germinal layer surrounded by acellular laminated layer and the most frequent AE morphological profile is characterised by intrahepatic heterogeneous, infiltrative mass with irregular outlines and necrotic centre that appear on USG as hypoechoic and hyperechoic lesions (Reuter et al., 2001; Vuitton et al., 2014).

Metacestode of $E$. granulosus presents as cyst/cysts localised predominantly in the liver and less frequently in lungs or other organs. Cyst germinal layer generates brood capsules and protoscoleces into a central cavity filled with liquid content. Sometimes, the development does not progress and the cysts remain sterile (non-fertile). Collapse of cysts walls and calcifications can sometimes occur, as well as the formation of "daughter" cysts of variable size inside or outside the "mother" cyst (Turčeková et al., 2009; Brunetti et al., 2010).

Clinical symptoms of both, $\mathrm{AE}$ and $\mathrm{CE}$, are unspecific and similar and depend on the cyst localisation. They usually occur when the metacestode compresses, infiltrates or ruptures to neighbouring structures. The symptoms of AE predominantly include abdominal pain, jaundice, fatigue, hepatomegaly and weight loss. In patients with cystic echinococcosis, upper abdominal pain, hypochondriac or epigastric discomfort, symptoms deriving from biliary tract, nausea and vomiting and weakness dominate (Yolasigmaz et al., 2006; Schneider et al., 2010).

The diagnosis of echinococcosis is based on the patient's anamnesis, clinical symptoms, morphological features identified by imaging techniques, serology and histology or examination of cyst punctate. Imaging methods provide useful information on the character of the cysts and together with serological results are very important in relation to diagnosis and prognosis of the disease. Moreover, serology plays a key role in long-term monitoring of the patient during the treatment or after surgical intervention (Yolasigmaz et al., 2006; Reiterová et al., 2014). Despite undoubtedly positive impact of serological methods on confirmation of diagnosis there are some negatives. Serological tests detect the presence of antibodies to different types of Echinococcus spp. antigens, with different values of sensitivity and specificity. Specificity of all tests is limited by occurrence of cross-reactions with other cestode infections (Brunetti et al., 2010). Cross-reactivity between AE and CE is detected quite often, for example ELISA with E. multilocularis somatic antigen showed $91.3 \%$ cross-reactions with sera of patients with CE in the study of Reiterová et al. (2014). Knapp et al. (2014), using E. multilocularis ELISA with rEm18 and Em2Em18 antigens detected positive results of serology in $25 \%$ and $31.25 \%$ of patients with cystic/polycystic echinococcosis. Authors therefore suggest the use of combination of different serological tests to obtain accurate diagnosis. In cystic echinococcosis, microscopic examination of hydatid cyst punctate obtained during diagnostic or therapeutic puncture (PAIR) is very useful diagnostic procedure in the case of positive finding of protoscoleces. However, there are also some limitations, as protoscoleces are not present in every patient and Skuhala et al. (2014) confirmed their presence only in $63.16 \%$ of patients with CE diagnosis.

In our case, the presence of one big round cyst with liquid content and multiple smaller "daughter" cysts round in shape, together with serological positivity to antigen $B$ of $E$. granulosus suggested the diagnosis of cystic echinococcosis. Refuse of radical surgery by patient and the improvement of clinical status and laboratory findings after the mebendazole therapy did not potentiate the need of further diagnostic process or radical (percutaneous/endoscopic) interventions, except regular control settings. After 6 months, due to intermittent pressure pain in the right hypochondriac area, elevation of GMT and unchanged results of CT examination, surgical revision and liver biopsy were performed. Subsequently, molecular analyses of liver tissue sample confirmed $E$. multilocularis as the etiological agent of the disease. Before surgery, our case could be classified as "possible" CE case according to suggestions of experts (Brunetti et al., 2010) and only the results of molecular examination allowed the final confirmation of the diagnosis.

In conclusion, unusual course and clinical picture of the disease imitating cystic echinococcosis in presented case report, together with limitations of serological tests confirmed the importance of accurate differential diagnosis of echinococcosis, especially in countries with simultaneous occurrence of several species of Echinococcus. Although every aspect of clinical and laboratory results is considered responsibly, sometimes only molecular techniques can solve the problem of differential diagnosis.

\section{Acknowledgement}

The research was supported by Slovak Grant Agency VEGA, projects No. 2/0127/13.

\section{References}

Antolová, D., Miterpáková, M., Škutová, M., Szilágyiová, M., HudAČKovÁ, D. (2014): Echinococcus multilocularis in Slovakia actual situation. Infovet, 21 (5): 245 - 249 (In Slovak)

Brunetti, E., Kern, P., Vuitton, D. A., Writing panel for the WHO-IWGE (2010): Expert consensus for the diagnosis and treat- 
ment of cystic and alveolar echinococcosis in humans. Acta Trop., 114: 1 - 16. DOI: 10.1016/j.actatropica.2009.11.001

Kern, P., Wen, H., Sato, N., Vuitton, D.A., Gruener, B., Shao, Y., Delabrousse, E., Kratzer, W., Bresson-Hadni, S. (2006): WHO classification of alveolar echinococcosis: Principles and application. Parasitol. Int., 55: S283 - S287. DOI: 10.1016/j.parint.2005.11.041 Kinčeková, J., Reiterová, K., Dubinský, P., Szilágyiová, M., Johanes, R.G.M. (2002): A second case of autochthonous human alveolar echinococcosis in the Slovak Republic. Helminthologia, 39 (4): $193-196$

Knapp, J., Sako Y., Grenouillet, F., Bresson-Hadni, S., Richou, C., Graguidi-Haore H., Ito, A., Millon, L. (2014): Comparison of the serological tests ICT and ELISA for the diagnosis of alveolar echinococcosis in France. Parasite, 21: 34. DOI: 10.1051/parasite/2014037

Manfredi, M.T., Di Cerbo, A.R., Zanzanl, S. (2013): Cystic echinococcosis in Lombardy: epidemiological aspects and spatial analysis. Helminthologia, 50 (2): 96 - 103. DOI: 10.2478/s11687-0130115-5

MiterPÁkovÁ, M., DubinskÝ, P. (2011): Fox tapeworm (Echinococcus multilocularis) in Slovakia - summarizing the long-term monitoring. Helminthologia, 48 (3): 155 - 161. DOI: 10.2478/s11687-011-0023-5 Nakao, M., Xiao, N., Okamoto, M., Yanagida, T., Sako, Y., Ito, A. (2009): Geographic pattern of genetic variation in the fox tapeworm Echinococcus multilocularis. Parasitol. Int., 58, 384 - 389. DOI:10.1016/j.parint.2009.07.010

Reiterová, K., Auer, H., Altintas, N., Yolasigmaz, K. (2014): Evaluation of purified antigen fraction in the immunodiagnosis of cystic echinococcosis. Parasitol. Res., 113: 2861 - 2867. DOI: 10.1007/ s00436-014-3947-0

Reuter, S., Nüssle, K., Kolokythas, O., Haug, U., Rieber, A., Kern, P., Kratzer, W. (2001): Alveolar liver echinococcosis: a comparative study of three imaging techniques. Infection, 29 (3): 119 - 125. DOI: 10.1007/s15010-001-1081-2

Schneider, R., Gollackner, B., Edel, B., Schmid, K., Wrba, F., TuCEK, G., WalochniK, J., Auer, H. (2008): Development of a new PCR protocol for the detection of species and genotypes (strains) of Echinococcus in formalin-fixed, paraffin-embedded tissues. Int. J. Parasitol., 38 (8-9): 1065 - 1071. DOI: 10.1016/j.ijpara.2007.11.008

Schneider, R., Gollackner, B., Schindl, M., Tucek, G., Auer, H. (2010): Echinococcus canadensis G7 (Pig strain): an underestimated cause of cystic echinococcosis in Austria. Am. J. Trop. Med. Hyg., 82 (5): 871 - 874. DOI: 10.4269/ajtmh.2010.09-0639

Skuhala, T., Stojčevič J., D., Desnica, B. (2014): Diagnostics of Echinococcus granulosus particles in hepatic cyst punctate of seropositive patients. Helminthologia, 51 (1): 63 - 66. DOI: 10.2478/ s11687-014-0209-8

Szilágyiová, M., HudeČKovÁ, H., Lauko, L'., PolÁČEK, H., Šimeková, K. (2001): Our experiences with the diagnostics and treatment of liver alveococcosis. Klin. Mikrobiol. Inf. Lék., 7 (9-10): 255 - 257 (In Slovak)

SzILÁgyiovÁ, M., Mištuna, D., KinČEKovÁ, J., PolÁČEK, H., KašÁKovÁ, L', JAKUBČÁKOVÁ, Cs. (2005): Occurence of human alveolar echinococcosis in Slovakia - diagnostic and therapeutic problems. Intern. Med., 5 (1): 36 - 39 (In Slovak)

SZILÁGYIOVÁ, M., PolÁČEK, H., ŠimeKOVÁ, K., KinČEKOVÁ, J., NovÁKOVÁ, E., BochničKovÁ, M. (2011): Cystic echinococcosis - metamorhoses of clinical picture. Gastroenterol. Prax, 10 (4): 214 - 215

Szilágyiová, M., Laca, L'., Šimeková, K., PolÁček, H., Antolová, D., NovÁKovÁ, E. (2014): Alveococcosis - serious helminthozoonosis threatening human life. Intern. Med., 14 (3): 115 - 118 (In Slovak)

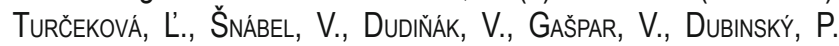
(2009): Prevalence of cystic echinococcosis in pigs from Slovakia, with evaluation of size, fertility and number of hydatid cysts. Helminthologia, 46 (3): 151 - 158. DOI: 10.2478/s11687-009-0029-4 Vuitton A. D., Bresson-HadnI, S. (2014): Alveolar echinococcosis: evaluation of therapeutic strategies. Expert Opin. Orphan Drugs, 2 (1): 67 - 86. DOI: 10.1517/21678707.2014.870033 Yolasigmaz, A., Reiterová K., Turk, M., Reyhan, E., Bozdag, A.D., Karababa, A.O., Altintas Nu., Altintas, Na. (2006): Comparison of serological and clinical findings in turkish patients with cystic echinococcosis. Helminthologia, 43 (4): 220 - 225. DOI: 10.2478/ s11687-006-0041-x 